virus infection was present in $29 \% .25 \%$ were treated with tenofovir plus protease inhibitors, and $47 \%$ with tenofovir plus a non-nucleoside reverse transcriptase inhibitor. The mean value of BMD in lumbar spine (LS) was $0.93 \mathrm{~g} / \mathrm{cm}^{2}$ (range: $0.84-1.02$ ) and in femoral neck (FN) $0.78 \mathrm{~g} / \mathrm{cm}^{2}$ (range: $0.69-0.86$ ). For the comparison with the ESOSVAL cohort the worst value of T-score in either LS or FN was chosen and patients were classified according to WHO definitions (osteoporosis $\leq-2.5$, osteopenia -1 to -2.5 ); the results are presented in the table. Only the data for the 50-64 and 65-74 years groups were compared because the number of older HIV patients in our center was small. Significant differences were found between the categories of osteoporosis in men in the 65-74 years old group, and that of osteopenia in women in the 55-64 years old group.

\begin{tabular}{|c|c|c|c|c|c|c|}
\hline & \multicolumn{2}{|c|}{$55-64 y$} & \multirow[t]{2}{*}{$p$-value } & \multicolumn{2}{|c|}{$65-74 y$} & \multirow[t]{2}{*}{$p$-value } \\
\hline & $\begin{array}{l}\text { HIV+ } \\
n=60\end{array}$ & $\begin{array}{c}\text { ESOSVAL } \\
n=2893\end{array}$ & & $\begin{array}{l}\mathrm{HIV+} \\
\mathrm{n}=16\end{array}$ & $\begin{array}{c}\begin{array}{c}\text { ESOSVAL } \\
n=1555\end{array}\end{array}$ & \\
\hline \multicolumn{7}{|l|}{ Males } \\
\hline T-score $\leq-2,5$ & $20 \%$ & $12.6 \%$ & 0.08798 & $44 \%$ & $11.2 \%$ & $0.00005^{\star}$ \\
\hline T-score -1 to $-2,5$ & $61 \%$ & $48.9 \%$ & $0.02888^{\star}$ & $63 \%$ & $59.2 \%$ & 0.79102 \\
\hline \multicolumn{7}{|l|}{ Females } \\
\hline T-score $\leq-2,5$ & $31 \%$ & $21 \%$ & 0.38845 & $50 \%$ & $29,8 \%$ & 0.37768 \\
\hline T-score -1 to $-2,5$ & $82 \%$ & $50.1 \%$ & $0.01296^{*}$ & $50 \%$ & $49,7 \%$ & 0.99107 \\
\hline
\end{tabular}

Conclusions: We observed a statistically significant increase in prevalence of osteoporosis in HIV-infected men in the 65-74 years group, and in osteopenia HIVinfected men in the 55-64 years group, in concordance with the presumed greater risk derived from a variety of causes (treatment, chronic inflammatory status, comorbidities, etc.). A non significant trend towards an increased prevalence of osteoporosis in the 55-64 years group, and in osteopenia in the 65-74 years group was seen. As for women, there was a statistically significant increase in osteopenia prevalence in the 55-64 years group with HIV and a non significant trend towards increased prevalence of osteoporosis in that age group, whereas no significant increase was observed in the 65-74 years HIV group, presumably due to the small number of patients included in it.

Disclosure of Interest: None declared

DOI: 10.1136/annrheumdis-2017-eular.6877

\section{FRI0546 COMPARISON OF MINERAL BONE DENSITY AND RISK FRACTURE ASSESSED BY THE FRAX TOOL IN HIV-INFECTED PATIENTS FOLLOWED IN A SPANISH TERTIARY HOSPITAL WITH THOSE OF NON HIV-INFECTED SPANISH POPULATION}

F. López Gutiérrez ${ }^{1}$, W.A. Sifuentes Giraldo ${ }^{1}$, M. Vázquez Díaz ${ }^{1}$, J.L. Casado Osorio ${ }^{2} \cdot{ }^{1}$ Rheumatology; ${ }^{2}$ Infectious Diseases, Ramon y Cajal University Hospital, Madrid, Spain

Background: The Fracture Risk Assessment Tool (FRAX) is a validated clinical fracture risk calculator that estimates 10-year risk of both major osteoporotic and hip fractures in the general population. However, its role in patients with human immunodeficiency virus (HIV) infection is still not clear because may underestimate their risk.

Objectives: To assess the bone mineral density (BMD) and 10-year fracture risk according to FRAX in HIV-infected patients followed in a tertiary hospital of Madrid and compare them with the ESOSVAL cohort, which included 11035 patients and is representative of the non-HIV population seen in Spanish tertiary hospitals. Methods: We performed a cross-sectional study in which FRAX and BMD values were determined in a prospective cohort that included HIV-infected patients seen our center during the period from 2010 to 2015. Collected data included demography, comorbidities, treatment, risk factors required for the FRAX calculation and densitometric variables.

Results: 97 patients from a total of a total of 311 had bone densitometry data and FRAX assessment available and were included in this study. The mean age of the patients was 55.4 years (range: $50-80$ ), 75 were men (77\%), most of them were Caucasians $(89 \%)$, with a mean body mass index of 24.2 (range: 15-32.7). Median time of HIV infection was 194 months (interquartile range [IQR]: 155.2- 259), median nadir of CD4+ cells was 168 (IQR: 81-308) and concomitant hepatitis C virus infection was present in $40 \%$. Among the risk factors included in FRAX calculation, $44 \%$ reported smoking, $10 \%$ inadequate alcohol consumption and $3 \%$ hyperthyroidism; there was no history of steroid therapy or previous fractures and only one had a family history of hip fracture. The mean value of BMD in lumbar spine (LS) was $0.9 \mathrm{~g} / \mathrm{cm}^{2}$ (range: 0.83-0.99) and in femoral neck (FN) $0.74 \mathrm{~g} / \mathrm{cm}^{2}$ (range: $0.65-0.82$ ). For the comparison with the ESOSVAL cohort the worst value of T-score in either LS or FN was chosen and the patients were classified according to WHO definitions; the results are presented in the table.

\begin{tabular}{lccccccc}
\hline & \multicolumn{2}{c}{ Men 50-64y } & $p$ & \multicolumn{2}{c}{ Women 50-64y } & $p$ \\
\cline { 2 - 3 } & $\begin{array}{c}\text { HIV } \\
(\mathrm{n}=68)\end{array}$ & $\begin{array}{c}\text { ESOSVAL } \\
(\mathrm{n}=2983)\end{array}$ & & $\begin{array}{c}\text { HIV } \\
(\mathrm{n}=21)\end{array}$ & $\begin{array}{c}\text { ESOSVAL } \\
(\mathrm{n}=3043)\end{array}$ & \\
\hline T-score $\leq-2,5$ & $14 \%$ & $12.6 \%$ & 0.606 & & $33 \%$ & $21 \%$ & 0.167 \\
T-score -1 to $-2,5$ & $56 \%$ & $48.9 \%$ & 0.255 & $52 \%$ & $50.1 \%$ & 0.834 \\
FRAX major fracture $\geq 10$ & $1.8 \%$ & $0.1 \%$ & $0.002^{*}$ & $2,36 \%$ & $0.6 \%$ & 0.015 \\
& $(0.4-5.1)$ & $(0-0.2)$ & & $(1.3-4.1)$ & $(0-1)$ & \\
FRAX hip fracture $\geq 3$ & $0.47 \%$ & $0.1 \%$ & $0.002^{*}$ & $0.57 \%$ & 0.7 & 0.702 \\
& $(0-3.5)$ & $(0 .-0.3)$ & & $(0-2)$ & $(0.4-1.1)$ & \\
\hline
\end{tabular}

Only the data for the 50-64 years group were compared because the number of older HIV patients in our center was small. No significant differences were found between the categories of osteopenia and osteoporosis in both genders, but there was a significant difference with respect to the risk of both major and hip fractures in males, being higher in patients with HIV infection compared to the population of the ESOSVAL cohort.

Conclusions: HIV-infected patients followed in our center do not show significant differences regarding the prevalence of osteopenia and osteoporosis compared to non-HIV Spanish population represented by the ESOSVAL cohort. However, a trend towards a lesser BMD is seen in all HIV infected groups. The fracture risk estimated by FRAX is significantly higher in HIV-infected men probably due to a higher frequency of associated risk factors.

Disclosure of Interest: None declared DOI: 10.1136/annrheumdis-2017-eular.6954

\section{FRI0547 OSTEOPOROSIS AND BONE METABOLISM IN SYSTEMIC SCLEROSIS}

Á. Horváth ${ }^{1}$, K. Gulyás ${ }^{1}$, H.P. Bhattoa ${ }^{2}$, G. Szücs ${ }^{1}$, Z. Szekanecz ${ }^{1}$ S. Szamosi ${ }^{1} .{ }^{1}$ Department of Rheumatology; ${ }^{2}$ Department of Laboratory Medicine, University of Debrecen, Faculty of Medicine, Debrecen, Hungary

Background: Systemic sclerosis (SSc) has been associated with bone loss and increased risk for bone fractures. Disease-related factors, age, corticosteroid therapy may be associated with increased bone turnover and bone loss.

Objectives: Here we performed a detailed study on osteoporosis in SSc. We performed bone density assessment by DXA, as well as peripheral forearm quantitative CT (pQCT). In addition, we assessed bone biomarkers and correlated bone- and disease-associated measures.

Methods: Altogether 44 SSc patients ( 36 women, 8 men; age: 64.1 years; disease duration: 17.6 years) were randomly recruited for the study. Bone density was assessed by DXA at the lumbar spine and femoral neck. PQCT (Stratec) is able to assess total, trabecular and cortical density. We also determined FRAX, levels of vitamin D, as well as bone markers (Ca, PTH, osteoclacin, P1NP, beta-CTX), markers of autoimmunity (ANA, ACA and anti-Scl70) and clinical manifestations of the disease. Statistical analysis was performed by SPSS v22.0.

Results: Vitamin D levels were lower $(53.9+/-36.8 \mathrm{nM})$ than the normal range (>75 nM). 34 out of 44 patients $(77 \%)$ had D-hypovitaminosis. Abnormally increased PTH, P1NP, OC, CTX levels were observed in 10, 7, 2 and 6 patients, respectively. Previous fractures occurred in 19 patients $(43 \%)$. The vertebral and hip FRAX values were $13.5 \%$ and $4 \%>$ respectively. By DXA, osteoporosis of the lumbar spine and hip was detected in 10 and 10 patients, while osteopenia were found in 16 and 20 patients, respectively. With respect to pQCT, total and trabecular bone density in SSc patients $\left(248.4\right.$ and $150.9 \mathrm{mg} / \mathrm{cm}^{3}$ ) was significantly lower than in healthy controls (354 and $193 \mathrm{mg} / \mathrm{cm}^{3}$, respectively). Higher OC levels were assocated with the diffuse form of SSc $(R=0.330, p=0.035)$. Longer disease duration correlated with lower $\mathrm{PQCT}$ total $(\mathrm{R}=-0.341, \mathrm{p}=0.023)$ and trabecular density $(R=-0.336, p=0.026)$. Interestingly, most bone markers ( $P 1 N P$, OC, CTX) positively correlated with gastrointestinal manifestations. Furthermore, pQCT total bone density was siognificantly lower in patients with pulmonary involvement, digital ulcer and anti-Scl70+.

Conclusions: A high proportion of SSc patients have osteopenia or osteoporosis, as well as low vitamin D levels. As determined by PQCT, trabecular loss is more common. Both total and trabecular bone loss, as well as bone markers may be associated with disease duration, anti-Scl70 and some organ manifestations. SSc patients should be screened and treated for osteoporosis.

Disclosure of Interest: None declared

DOI: 10.1136/annrheumdis-2017-eular.3645

\section{FRI0548 INFLUENCE OF HOMOCYSTEINE AND VERTEBRAL FRACTURES ON PREVALENT ABDOMINAL AORTIC CALCIFICATION IN POSTMENOPAUSAL WOMEN: A MULTICENTRIC CROSS-SECTIONAL STUDY}

I. Ghozlani ${ }^{1}$, A. El Maataoui ${ }^{2}$, M. Ghazi ${ }^{3}$, A. Kherrab ${ }^{3}$, R. Niamane ${ }^{3}$ ${ }^{1}$ Rheumatology Department, Military Hospital; ${ }^{2}$ Chemistry-Biochemistry Department, Faculty of Medicine and Pharmacy, Ibn Zohr University, Agadir; ${ }^{3}$ Rheumatology Department, Military Hospital Avicenne, Marrakech, Morocco

Background: Osteoporosis and cardiovascular diseases are two major public health problems. Both are associated with high morbidity, long-term hospitalization, mortality and loss of independence leading to institutionalization. Vertebral morphometry using dual-energy X-ray absorptiometry (DXA) also known as vertebral fracture assessment (VFA) is a fast, low-radiation technique which produces images that are of sufficient quality to be used to diagnose the presence of vertebral deformity consistent with fracture. VFA has demonstrated utility for vertebral visualization and thus is an important tool for fracture detection in women and men. It has been shown also in many populations that this technique can simultaneously identify abdominal aortic calcification (AAC). Hyperhomocysteinemia, a condition that recent epidemiological studies have shown to be associated with increased risk of vascular disease. A potential role of homocysteine in bone fragility has been considered from the observation of a high prevalence of osteoporosis in subjects with homocystinuria. 